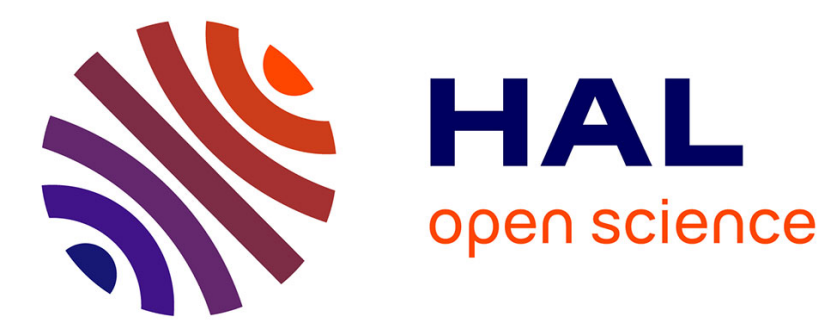

\title{
Prompt microwave-assisted synthesis of carbon coated Si nanocomposites as anode for lithium-ion batteries
}

\author{
Ali Uctepe, Emrah Demir, Burak Tekin, Burcu Dursun, Osman Ozturk, \\ Ozlem Sel, Rezan Demir-Cakan
}

\section{- To cite this version:}

Ali Uctepe, Emrah Demir, Burak Tekin, Burcu Dursun, Osman Ozturk, et al.. Prompt microwaveassisted synthesis of carbon coated Si nanocomposites as anode for lithium-ion batteries. Solid State Ionics, 2020, 354, pp.115409. 10.1016/j.ssi.2020.115409 . hal-03094410

\section{HAL Id: hal-03094410 https: / hal.sorbonne-universite.fr/hal-03094410}

Submitted on 4 Jan 2021

HAL is a multi-disciplinary open access archive for the deposit and dissemination of scientific research documents, whether they are published or not. The documents may come from teaching and research institutions in France or abroad, or from public or private research centers.
L'archive ouverte pluridisciplinaire HAL, est destinée au dépôt et à la diffusion de documents scientifiques de niveau recherche, publiés ou non, émanant des établissements d'enseignement et de recherche français ou étrangers, des laboratoires publics ou privés. 


\title{
Prompt Microwave-Assisted Synthesis of Carbon Coated Si Nanocomposites as Anode for Lithium-Ion Batteries
}

\author{
Ali Uctepe ${ }^{\mathrm{a}, \mathrm{b}}$, Emrah Demir ${ }^{\mathrm{b},}$, Burak Tekin ${ }^{\mathrm{a}, \mathrm{b}}$, Burcu Dursun ${ }^{\mathrm{b}, \mathrm{c}}$, Osman Ozturk ${ }^{\mathrm{b}, \mathrm{d}}$, Ozlem Sel $^{\mathrm{e}}$, Rezan \\ Demir-Cakan $^{\mathrm{a}, \mathrm{b}^{*}}$ \\ ${ }^{a}$ Department of Chemical Engineering, Gebze Technical University, 41400, Gebze, Kocaeli, Turkey \\ ${ }^{b}$ Institute of Nanotechnology, Gebze Technical University, 41400, Gebze, Kocaeli, Turkey \\ ${ }^{c}$ Department of Material Science and Engineering, Gebze Technical University, 41400, Gebze, \\ Kocaeli, Turkey \\ ${ }^{d}$ Department of Physics, Gebze Technical University, 41400, Gebze, Kocaeli, Turkey \\ ${ }^{e}$ Sorbonne Université, CNRS, Laboratoire Interfaces et Systèmes Electrochimiques, LISE UMR8235, \\ 75005 Paris, France
}

*Corresponding author e-mail address: demir-cakan@gtu.edu.tr

\begin{abstract}
Hard carbons derived from glucose and glucosamine are synthesized via microwave-assisted hydrothermal carbonization (HTC) and subsequent pyrolysis treatment to be used as anode materials for lithium-ion batteries (LIBs). Related to the limited lithium ion intercalation to graphite $\left(\mathrm{LiC}_{6}\right)$ resulting relatively low theoretical capacity $(372 \mathrm{mAh} / \mathrm{g})$, silicon is considered as one of the most appealing anode materials for LIBs by exhibiting very high theoretical capacity $\left(3578 \mathrm{mAh} / \mathrm{g}\right.$, based on $\mathrm{Li}_{15} \mathrm{Si}_{4}$ ). However, silicon suffers from huge volume expansion during intercalation of lithium ions which causes rapid capacity fading. One of the most practical strategy to suppress this problem is to coat the silicon nanoparticles with carbonaceous materials. Herein, silicon is coated via microwave-assisted hydrothermal carbonization method in the presence of glucose or glucosamine which are then further pyrolyzed at $750^{\circ} \mathrm{C}$ to obtain silicon-carbon composite anodes. Composite containing glucosamine (SiGA-C-750) enables N-doped carbon evidenced by EDX and XPS analyses which contributes to obtain much enhanced electrochemical properties than that of glucose containing composite (Si-G-C-750). Additionally, higher $\mathrm{Li}^{+}$diffusion coefficient and smaller resistance values attest the advantageous nature of the $\mathrm{N}$-doped anode material.
\end{abstract}

Keywords: Microwave Synthesis; Lithium-ion batteries; Silicon; Carbon, Hydrothermal Carbonization 


\section{Introduction}

Li-ion batteries (LIBs) are considered as one the most widespread rechargeable energy storage technologies in portable electronic devices due to their good cycle life, high energy density and power[1]. However, with the increasing demand to those commercial devices, there is an urgent need to develop LIBs with even higher energy density, coulombic efficiency and excellent rate performance. In addition to these issues, the cost and environmental concern of LIBs are needed to be considered. Graphite is the most commonly used anode materials of LIBs especially for commercial applications that provide relatively low theoretical capacity $\left(372 \mathrm{mAh} / \mathrm{g}, \mathrm{LiC}_{6}\right)$ due to the limited intercalation of lithium ions into the graphite[2]. Therefore, there has been an enormous effort to develop new anode materials. Silicon is a lithium alloying element and regarded as one of the most promising anode material by exhibiting the highest theoretical capacity $\left(3578 \mathrm{mAh} / \mathrm{g}\right.$, based on $\left.\mathrm{Li}_{15} \mathrm{Si}_{4}\right)$ among the existing elements on earth as well as being cost-effective, abundant and non-toxic. However, the practical usage of silicon powders alone are largely restricted owing to the poor conductive nature of $\mathrm{Si}$ as well as exhibiting large volume expansion (up to $400 \%$ ) during the insertion of lithium ions[3]. Such a volume expansion causes rapid capacity fading and low coulombic efficiency owing to the pulverization of silicon electrode, loss of electrical contact between current collector and electrode and formation of unstable thick solid electrolyte interphase (SEI) $[4,5]$.

Up to now, to solve the above described problems and improve the electrochemical properties of silicon, several strategies have been employed such as using of silicon-thin film electrodes[6-8], development of new binders with self-healing properties [9-11], employing nanostructured electrodes[12, 13], alloying with different metals[14-16] and preparation of silicon/carbon composites[17, 18]. Among them, silicon/carbon composites have attracted considerable attention in which carbon buffers to eliminate mechanical stress caused by the huge volume expansion of $\mathrm{Si}$, as well as improves the conductivity of overall composite.

Recently, carbohydrates such as glucose, glucosamine and chitosan have been used as a carbon source to prepare $\mathrm{Si} / \mathrm{C}$ composite anode materials for LIBs in a low cost and environmentally friendly approach. Kim et al. reported the usage of glucose and glucosamine hydrochloride to obtain carbon-silicon (C-Si) and N-doped carbon-silicon anode materials, respectively. Electrochemical results indicated the positive impact of carbon on the capacity performances of silicon especially when carbon is doped with nitrogen[19]. Apart from that, Liu et al. reported on the performance of silicon/graphite/carbon composite as an anode material prepared via facile spray drying with subsequent pyrolysis in which chitosan was used as N-containing carbon precursor and dispersion agent[20]. In another study, spherical carbon/silicon composite anode preparation was reported and employed hydrothermal carbonization (HTC) of glucose in the presence of silicon particles with a subsequent pyrolysis step[21]. HTC is a cheap, green and sustainable method that enables to convert biomasses into valuable 
carbonaceous materials in the presence of water under saturated pressure at low temperatures (180-250 $\left.{ }^{\circ} \mathrm{C}\right)[22-25]$. Apart from conventional HTC method, microwave-assisted HTC has emerged as an energy efficient approach that enables the conversion of biomasses into useful products by reducing the process time and cost[26].

Herein, taking this approach one step further, compared with the conventional HTC method normally employed in an autoclave with a reaction time varying between 20 - 48h, the microwave assisted method has been employed which gives rise to much rapid material synthesis $(<2 \mathrm{~h})$ resulting less energy consumption and better homogeneity at the structure. To do so, glucose (G) and glucosamine hydrochloride (GA) carbohydrates were used as carbon precursors. To the best of our knowledge, microwave-assisted HTC process applying glucose and glucosamine as a carbon source to enhance the electrochemical properties of silicon has not been subjected thus far. Morphological and structural characterizations of hydrochars and pyrolyzed anode materials were performed via SEM, EDX, TEM, TGA, XRD and XPS. Electrochemical properties of anode materials were evaluated via cyclic voltammetry $(\mathrm{CV})$, electrochemical impedance spectroscopy (EIS) and galvanostatic charge/discharge tests with rate performance.

\section{Experimental}

\subsection{Preparation of hard carbon anode materials}

Glucose (Sigma Aldrich) and glucosamine hydrochloride (Alfa Aesar) were employed as carbon sources to produce hard carbon anode materials (named as G-C-750 and GA-C-750). 0.5 gram of each carbon precursor was dispersed in $10 \mathrm{~mL}$ of water and then subjected to microwave-assisted heat treatment at $200^{\circ} \mathrm{C}$ for 2 hours for glucose and 1 hour for glucosamine. $30 \mathrm{~mL}$ glass vessels from Anton Parr (Model no Monowave 300) are used for the synthesis. After microwave treatment, the resulting dispersions were washed with distilled water and ethanol via centrifugation for several times until the colour of the supernatants became completely clear, and finally the precipitated products were dried at $80{ }^{\circ} \mathrm{C}$ in a vacuum oven. The yield is around $4 \%$ for the glucose and around $10 \%$ for the glucosamine solutions as shown in Table SI-1. Even though the yield is low at first glance, same glucose/glucosamine solution can be used several times to obtain either carbonaceous product or Si-C composites without wasting the precursors. In a subsequent step, dried powder samples were pyrolyzed at $750{ }^{\circ} \mathrm{C}$ for 6 hours under inert nitrogen atmosphere to give hard carbon anode materials. During pyrolyzation step inevitable weight loss originated from the loss of the functional groups are also observed. 


\subsection{Preparation of silicon-carbon (Si-C) composite anode materials}

Figure 1 schematically displays the synthesis conditions of silicon containing anode materials (Si-G-C750 and Si-GA-C-750). Silicon-carbon (Si-C) composites were prepared via the mixtures of silicon (Sigma Aldrich) and carbon precursor (glucose or glucosamine) with the aim of reaching $50 \mathrm{wt} . \% \mathrm{Si}$ contents for both composites. The mixture of silicon and carbon precursors (glucose or glucosamine) was firstly subjected to microwave-assisted hydrothermal treatment (HTC). For the first composite material, $0.5 \mathrm{~g}$ of glucose and $0.0110 \mathrm{~g}$ of silicon were dispersed into $10 \mathrm{ml}$ of deionized water and then subjected to the microwave-assisted hydrothermal carbonization at $200{ }^{\circ} \mathrm{C}$ for 2 hours. Upon microwave treatment, Si-hydrocarbon composite was washed via centrifugation of resulting solution in distilled water and ethanol several times until the supernatant became clear. For the second composite material, a mixture of $0.5 \mathrm{~g}$ of glucosamine hydrochloride and $0.0273 \mathrm{~g}$ of silicon was dispersed into $10 \mathrm{ml}$ of deionized water and the microwave treatment with the subsequent centrifugation process were applied as described above by keeping the microwave treatment time for 1 hour. Subsequently, purified silicon containing hydrochars (Si-G-HTC and Si-GA-HTC) were pyrolyzed at $750{ }^{\circ} \mathrm{C}$ for 6 hours under $\mathrm{N}_{2}$ atmosphere to obtain Si-G-C-750 and Si-GA-C-750.

\subsection{Physical characterisations}

The microstructure, surface morphology and chemical composition of the materials were evaluated by a wide range of characterization techniques. Morphology of pyrolyzed hard carbon anode materials were investigated via Transmission electron microscope (TEM) (JEOL JEM 100CX) and scanning electron microscope (SEM) (Philips XL30). TGA measurements (PerkinElmer, 4000) of Si-G-C-750 and Si-GAC-750 composite anode materials were carried out under oxygen atmosphere at a heating rate of $10{ }^{\circ} \mathrm{C}$ $\mathrm{min}^{-1}$ between room temperature and $800{ }^{\circ} \mathrm{C}$ to determine the silicon percentage within the composites. In addition to that, blank experiments without carbon sources (namely Si particles) were performed by TGA up to $1400^{\circ} \mathrm{C}$ under air with a heating rate of $5^{\circ} \mathrm{C} \mathrm{min}^{-1}$. Elemental distributions of silicon-carbon composites were analyzed via Energy Dispersive X-ray (EDX) Spectroscopy coupled to the SEM. Bruker D8 Advance diffractometer ( $\theta-2 \theta$ mode, $\mathrm{Cu} \mathrm{K} \alpha$ radiation, $\lambda=1.5406)$ was used between $2 \theta=(2-$ $90^{\circ}$ ) at a scan step of $0.02^{\circ} / \mathrm{s}$ to record the X-ray powder diffraction patterns of the samples. Surface electronic and compositional properties of Si-G-C-750 and Si-GA-C-750 (N-doped) were compared via $\mathrm{X}$-Ray Photoelectron Spectroscopy (XPS) which is equipped with charge analyzer Phoibos 150 Specs and conventional X-Ray source ( $\mathrm{Al} \mathrm{K} \alpha$ and $\mathrm{Mg} \mathrm{K} \alpha$ ).

\subsection{Electrochemical measurements}

Galvanostatic charge/discharge measurements of the anode materials (G-C-750, GA-C-750, Si-G-C750 and Si-GA-C-750) were conducted using the Neware cycling station with coin cells that were assembled in an Argon filled glovebox and were cycled in the voltage range of 0.010-1.500 V or 0.010- 
$2.000 \mathrm{~V}$ vs Li/Li ${ }^{+}$. Cyclic Voltammetry (CV), electrochemical impedance spectroscopy (EIS) and rate capability tests were carried out utilizing a Biologic VMP-3 electrochemical workstation with Swagelok type cells that assembled in an Argon filled glovebox. CV tests were carried out at a scan rate of 0.1 $\mathrm{mV} / \mathrm{s}$ in the voltage range of $0.05-1.500 \mathrm{~V}$ vs Li/ $\mathrm{Li}^{+}$. EIS tests of Si-G-C-750 and Si-GA-C-750 were performed before and after C-rate tests, in the frequency range from $1 \mathrm{MHz}$ to $10 \mathrm{mHz}$ with a small potential perturbation amplitude of $5 \mathrm{mV}$.

Electrode slurries were prepared by mixing active material (G-C-750, GA-C-750, Si-G-C-750 and SiGA-C-750), conducting agent (Super P carbon) and carboxymethyl cellulose (CMC) binder in a weight ratio of 80:10:10 in water. The mixtures were stirred for 24 hours at ambient conditions, subsequently coated on copper foil using a doctor blade and dried in a vacuum oven at $60{ }^{\circ} \mathrm{C}$ for overnight. Lithium metal foil (Sigma Aldrich) was used as both counter and reference electrodes while glass fibre (Whatman) as a separator. $1 \mathrm{M}$ lithium hexafluorophosphate $\left(\mathrm{LiPF}_{6}\right)$ (Sigma Aldrich) dissolved in ethylene carbonate (EC) (Sigma Aldrich) and dimethyl carbonate (DMC) (Sigma Aldrich) mixture with a volume ratio of $1: 1$ containing $5 \mathrm{wt} \%$ fluoroethylene carbonate (FEC) additive (Alfa Aesar) was used as an electrolyte. The mass loading of active materials on copper foil was around $1.2-1.7 \mathrm{mg} / \mathrm{cm}^{2}$. The galvanostatic rate is given as $\mathrm{C} / \mathrm{n}$, where $\mathrm{C}$ is the capacity of the cell and $\mathrm{n}$ is the number of hours for totally charging or discharging the cell. Thus, during the electrochemical performance, $1 \mathrm{C}$ is equivalent to $3.7 \mathrm{~A} / \mathrm{g}$ for Si-G-C-750 and Si-GA-C-750 and $0.3 \mathrm{~A} / \mathrm{g}$ is for G-C-750, GA-C-750 materials.

\section{Results and Discussion}

\subsection{Synthesis and material characterisations}

Initially, bare carbon precursors (glucose or glucosamine) or silicon particles in the presence of carbon precursors were converted into hydrochars via microwave-assisted HTC method to obtain G-HTC, GAHTC, Si-G-HTC, Si-GA-HTC. Later on, these hydrochars were pyrolyzed at $750{ }^{\circ} \mathrm{C}$ and converted into carbonaceous materials (G-C-750, GA-C-750) and silicon/carbon composite anode materials (Si-G-C750, Si-GA-C-750). The carbonization temperature was kept below $900{ }^{\circ} \mathrm{C}$ in order to eliminate silicon carbide formation which is known to be inactive in reacting with $\mathrm{Li}$ ions and consequently hinders $\mathrm{Li}$ ion diffusion into the Si [27]. SEM images of glucose derived both silicon free and silicon containing anode materials (G-C-750 and Si-G-C-750) (Figures 2a and 2c) revealed the spherical morphology with a narrow size distribution. Glucosamine derived anode materials (GA-C-750 and Si-GA-C-750) resulted in an interconnected network of micron sized particles made of smaller particles (Figures $\mathbf{2 b}$ and $\mathbf{2 d}$ ). TEM images of silicon containing Si-GA-C-750 composite (Figures 2e and 2f) revealed a core/shell structure. Although it is difficult to assess the exact dimensions of the core/shell structure due to the interconnected network morphology, it is noted that the resulting composite spheres have an average diameter of 50-160 nm crystalline silicon core, which was covered by a non-uniformly coated shell layer 
of amorphous carbon with a thickness of around $20 \mathrm{~nm}$. It can be easily assumed that the later may have a function of buffering to prevent the undesired chemical reactions between electrolyte and silicon during electrochemical cycling. Besides, carbon shell may attract the Li-ions during the cell operation and be beneficial for diffusion of Li-ions in the electrode-electrolyte interface.

Thermal Gravimetric Analysis (TGA) measurements were performed under the oxygen atmosphere to determine the percentage of silicon content in the Si-Carbon composites (Figure SI-1 in supporting information). The small amount of weight losses observed up to $400{ }^{\circ} \mathrm{C}$ can be attributed to the removal of the adsorbed water in the Si-G-C-750 and Si-GA-C-750 samples. Following this small variation, TGA curves exhibit rapid weight losses between $400{ }^{\circ} \mathrm{C}$ and $550{ }^{\circ} \mathrm{C}$ due to the thermal degradation (combustion) of carbon-based material in the composite anodes. The remaining component is assumed to be silicon. Thus, pure Si contents as weight percentage were determined to be $\sim 44 \%$ and $\sim 45 \%$ in Si-G-C-750 and Si-GA-C-750, respectively. Additionally, it is important to verify the reactivity of silicon in water under microwave-assisted synthesis conditions. For instance, it has been reported that ball milling of silicon in water results rapid formation of $\mathrm{H}_{2}$ and $\mathrm{SiO}_{2}\left(\mathrm{Si}(\mathrm{s})+2 \mathrm{H}_{2} \mathrm{O}(\mathrm{l}) \rightarrow \mathrm{SiO}_{2}(\mathrm{~s})+\right.$ $\left.2 \mathrm{H}_{2}(\mathrm{~g})\right)$ [28]. Silicon particles have been also partially oxidized either by contact with water or by air heating at elevated temperatures to be able to prepare stable aqueous slurries for the realization of largescale Si-based electrodes [29]. Thus, blank experiments without carbon sources were performed by TGA up to $1400{ }^{\circ} \mathrm{C}$ under air. Figure SI-2 demonstrates the silicon nanoparticles treated at 1 or 2 hours in microwave oven in water. Indeed, the full oxidation of pure $\mathrm{Si}\left(\mathrm{Si} \rightarrow \mathrm{SiO}_{2}\right)$ above $100{ }^{\circ} \mathrm{C}$ theoretically should result weight gain from 28 (molecular weight of $\mathrm{Si}$ ) to 60 (molecular weight of $\mathrm{SiO}_{2}$ ) [29]. According to the TGA experiments, Si nanoparticles in water after 1-hour microwave treatment caused $20 \mathrm{wt} . \%$ silicon oxide $\left(\mathrm{SiO}_{\mathrm{x}}\right)$ formation while 2-hour microwave treatment caused around $29 \mathrm{wt} . \%$. This in-situ formed $\mathrm{SiO}_{\mathrm{x}}$ layers known to be beneficial for the electrochemical performances [30].

Figure 3a displays the X-ray diffraction (XRD) patterns of the GA-C-750 hard carbon and Si-GA-C750 composite anode materials. GA-C-750 hard carbon possesses two broad peak correspond to the (0 $\left.\begin{array}{ll}0 & 2\end{array}\right)$ and $\left(\begin{array}{lll}1 & 0 & 0\end{array}\right)$ diffraction modes at around $23^{\circ}$ and $43^{\circ}$ indicating the amorphous structure of the material. The XRD peak of the Si-GA-C-750 composite displays the well crystalline silicon nanoparticle structure, which demonstrates the absence of any impurity phases after the microwave treatment. Si-GC-750 also has similar XRD profile with Si-GA-C-750 (data not shown). Although as mentioned above $\mathrm{SiO}_{\mathrm{x}}$ is formed during the microwave-assisted synthesis conditions in water (Figure SI-2), crystalline $\mathrm{SiO}_{\mathrm{x}}$ phase were not observed with the XRD analysis. The elemental analysis performed via EDX (Figures 3b and 3c) showed the presence of C, O and Si elements, identified in both Si-G-C-750 and Si-GA-C-750 composites. Additional N element was observed for Si-GA-C-750 which indicates the successful formation of $\mathrm{N}$-doped carbon which is expected to improve the conductivity and electrochemical properties of the material. The usage of nitrogen containing carbons is beneficial for 
battery electrodes since the incorporation of nitrogen heteroatom into the carbon structure contributes to electron transport in the conduction band.

X-ray photoelectron spectroscopy (XPS) analysis (Figure 4) was carried out to investigate the chemical and electronic state of elements present in both silicon/carbon composites and to prove the nitrogen existence in the Si-GA-C-750. The XPS survey spectra demonstrated the existence of atoms in intermediate oxidation states such as $\mathrm{Si} 2 \mathrm{p}$ at $101.5 \mathrm{eV}$, Si2s at $154.5 \mathrm{eV}, \mathrm{C} 1 \mathrm{~s}$ at $298 \mathrm{eV}$ and $\mathrm{O} 1 \mathrm{~s}$ at 535 $\mathrm{eV}$ as shown in Figure 4a. In addition, the high-resolution N1s peak expectedly appeared at binding energy value of about $400 \mathrm{eV}$ in Si-GA-C-750 spectrum, which corresponds to characteristic peaks of pyridinic nitrogen, pyrrolic nitrogen and graphitic nitrogen with binding energy values of $398.7 \mathrm{eV}$, $401.3 \mathrm{eV}$ and $402.2 \mathrm{eV}$, respectively (Figure $\mathbf{4 b}$ ). These different N-bonding configurations are considered beneficial by contributing to the cycling efficiency which resulted from increased electrical conductivity and reduced Li-ion diffusion barrier[31].

\subsection{Electrochemical characterisations}

Figure 5 displays the cyclic voltammograms (CV) of the pyrolyzed carbons and silicon-carbon composites. According to CV of G-C-750, as shown in Figure 5a, cathodic peaks located at $1.51 \mathrm{~V}$, $0.54 \mathrm{~V}$ and near $0 \mathrm{~V}$ vs Li $/ \mathrm{Li}^{+}$for the $1^{\text {st }}$ cycle correspond to the formation of SEI resulting from the decomposition of electrolyte and irreversible insertion of lithium to the pyrolyzed glucose. Disappearance of these peaks in the following cycles indicates a stable SEI formation, cycling stability and occurrence of irreversible capacity loss during the $1^{\text {st }}$ cycle. Additionally, anodic peaks observed at $0.12 \mathrm{~V}$ and $1.04 \mathrm{~V}$ in the reverse cycles are attributed to lithium extraction from pyrolyzed glucose. Similar electrochemical response was also observed with the N-doped GA-C-750 anode in which the peaks at $1.43 \mathrm{~V}, 0.47 \mathrm{~V}$ and near $0 \mathrm{~V}$ for the negative potential scan and the peaks at $0.23 \mathrm{~V}$ and $1.05 \mathrm{~V}$ for the positive potential scan reflect the typical features of carbonaceous anode materials (Figure 5b). Regarding the $\mathrm{CV}$ of silicon-carbon composites (Figure 5c and 5d), cathodic peaks observed at $0.25 \mathrm{~V}$ and $1.25 \mathrm{~V}$ for Si-G-C-750 and located at $0.35 \mathrm{~V}$ and $1.20 \mathrm{~V}$ for Si-GA-C-750 correspond to the decomposition of electrolyte and formation of SEI film. The sharp peaks near $0 \mathrm{~V}$ during the first cathodic scan for both silicon-carbon composites are attributed to the formation of lithium silicide phase $\left(\mathrm{Li}_{\mathrm{x}} \mathrm{Si}\right)$ through the lithiation of crystalline silicon. The peaks observed in the first cathodic scan vanish in the following cycles which indicate the completion of SEI formation that facilitates high cycling stability and superior cycling performance during cell operation. Regarding the reverse cycles of siliconcarbon composites, observation of anodic peaks at $0.35 \mathrm{~V}$ and $0.55 \mathrm{~V}$ for Si-G-C-750 and at $0.32 \mathrm{~V}$ and $0.50 \mathrm{~V}$ for Si-GA-C-750 are attributed to the extraction of Li-ions from Si-host structure. The currents 
were plotted for per gram composite to compare the redox performances of Si-G-C-750 and Si-GA-C750. The fact that current values extracted from Si-GA-C-750 electrode are greater than the Si-G-C-750 electrode indicates the contribution of $\mathrm{N}$-doped carbon shell to the electrochemical properties. Besides the effect of nitrogen dopant, further explanation of the improved cycling performances could be the self-healing properties of the glucosamine as indicated with the chitosan [32] (that is a linear polysaccharide composed of randomly distributed glucosamine) via the hydrogen bonding between glucosamine and silicon nanoparticles.

Figure 6a shows the first cycle galvanostatic charge/discharge profiles of pyrolyzed carbons (G-C-750, GA-C-750) and pyrolyzed silicon-carbon composites (Si-G-C-750 and Si-GA-C-750) at a current density of $0.2 \mathrm{C}$ (1 C equivalents to $300 \mathrm{~mA} / \mathrm{g}$ for pyrolyzed carbons and $3700 \mathrm{~mA} / \mathrm{g}$ for the $\mathrm{Si} / \mathrm{C}$ composites). Initial Coulombic efficiency values for G-C-750, GA-C-750, Si-G-C-750 and Si-GA-C750 were $45,60,47$ and $76 \%$, respectively. The voltage curves reflect the typical electrochemical features of silicon or carbon anodes that also corroborates well with the $\mathrm{CV}$ results discussed previously. It can be clearly observed that both Si-G-C-750 and Si-GA-C-750 composites display long and flat plateaus during the first discharge corresponding the formation of SEI layer and lithiation of silicon. It is also noted that $\mathrm{Li}_{15} \mathrm{Si}_{4}$ alloy may form below $0.1 \mathrm{~V}$ (vs $\mathrm{Li}$ ) during lithiation that latter cause huge volume expansion [33]. As indicated by the dQ / dV plots (Figure SI-3) of Figure 6a, the charge is mainly composed by a plateau at $0.43 \mathrm{~V}$ (vs Li) with silicon-carbon composites meaning that silicon particles are electrochemically active and delithiated upon charging. On the contrary, there is no peak was observed at around $0.4 \mathrm{~V}$ (vs Li) with the glucose and glucosamine composites (Figure SI-3). Figure $6 \mathbf{b}$ exhibits the cycle performance of pyrolyzed carbon and silicon-carbon composite anode materials. G-C-750 and GA-C-750 anode materials delivered a discharge capacity values of 151 and $164 \mathrm{mAh} / \mathrm{g}$ presenting a capacity retention of 60 and $57 \%$ after 50 cycles, respectively. Si-G-C-750 and Si-GA-C-750 composite anode materials exhibited 551 and $1221 \mathrm{mAh} / \mathrm{g}$ of discharge capacities after 50 cycles that correspond to 40 and $39 \%$ capacity retention, respectively. It was clearly observed that coating of silicon particles with carbon layer enabled an enhanced capacity performance since carbon prevented the direct contact between silicon and electrolyte which also eliminated the possibility of unstable SEI formation[17]. Even though the capacity retention is slightly lower with the Si-GA-C-750 composite, much higher capacities are achieved due to the inherently higher conductivity from N-doped containing carbon structures.

The rate performances of G-C-750, GA-C-750 reference samples were evaluated at different current densities $(\mathrm{C} / 5, \mathrm{C} / 2, \mathrm{C}, 2 \mathrm{C}, 5 \mathrm{C})$ as shown in Figures 6c and $\mathbf{6 d}$. The average discharge capacity values for G-C-750 were 259, 194, 163, 141 and $105 \mathrm{mAh} / \mathrm{g}$ at current densities of C/5 (except first cycle), C/2, $\mathrm{C}, 2 \mathrm{C}$ and $5 \mathrm{C}$, respectively. After 30 cycles, when the current density restored to $\mathrm{C} / 5,219 \mathrm{mAh} / \mathrm{g}$ discharge capacity was obtained that correspond to capacity retention of $84 \%$ (Figure 6c). The same evaluation of the rate performance of GA-C-750 exhibited average discharge capacity values of 274 , 
$209,180,153$ and $116 \mathrm{mAh} / \mathrm{g}$, with the respective current density values employed as indicated in Figure 6c. After 30 cycles, when the current density returned to $\mathrm{C} / 5$, discharge capacity was recovered to $225 \mathrm{mAh} / \mathrm{g}$ indicating the stability and reversibility of the electrodes. The rate performances of silicon-carbon composites (Si-G-C-750 and Si-GA-C-750) were also performed varying the current densities from $\mathrm{C} / 5$ to $5 \mathrm{C}$ as demonstrated in Figure 6d. Si-G-C-750 anode material exhibited average discharge capacity value of $860 \mathrm{mAh} / \mathrm{g}$ at $\mathrm{C} / 5$. With changing the current densities from $\mathrm{C} / 2$ to $2 \mathrm{C}$, average discharge capacity values were obtained to be 667 and $433 \mathrm{mAh} / \mathrm{g}$, respectively. A reasonable capacity value of $238 \mathrm{mAh} / \mathrm{g}$ was achieved at the highest current density of $5 \mathrm{C}$. When the current density was returned to $\mathrm{C} / 5$, average discharge capacity was recovered to $615 \mathrm{mAh} / \mathrm{g}$. For the Si-GA-C-750 anode, average discharge capacity value was $2210 \mathrm{mAh} / \mathrm{g}$ at $\mathrm{C} / 5$. When the current density increased to $5 \mathrm{C}$, the average capacity decreased to $525 \mathrm{mAh} / \mathrm{g}$. As the current density restored to $\mathrm{C} / 5$, discharge capacity value was recovered to $905 \mathrm{mAh} / \mathrm{g}$ (compared with $615 \mathrm{mAh} / \mathrm{g}$ of Si-G-C-750) indicating the advantageous nature of $\mathrm{N}$-doping of the carbon layer which improved the cycling stability and electrochemical properties of the silicon anode.

EIS analyses were conducted to gain further insight into the electrochemical behavior of silicon-carbon composite anode materials obtained with two different carbon precursors in two electrode configuration where Li used as both reference and counter electrodes. It should be noted that compared to threeelectrode EIS measurements, in two-electrode test impedance of lithium metal may affect the value and shape of the full cell impedance [34]. Figures 7a and $\mathbf{7 b}$ show typical Nyquist diagrams of the Si-G-C750 and Si-GA-C-750 performed at OCV before and after C-rate tests (after 100 cycles). The EIS responses of both anode compositions before C-rate tests yield (i) depressed semicircles (which can be composed of two "not well-separated" semicircles) at the high frequency (HF) region and (ii) a sloping upward line at the low frequency (LF) region (Figure 7a). The depressed semicircles expanding from high to medium frequency region are ascribed to the formation of SEI layer and/or charge-transfer process at the interphase between the composite silicon-carbon electrode and electrolyte[35, 36]. The extrapolation to the real part of the impedance of the depressed semicircles towards lower frequencies enables the charge transfer resistance values to be estimated. In this case, the final point of the depressed semi arc at medium frequency in the Nyquist diagram can be defined as the total resistance or impedance $\left(\mathrm{R}_{\text {total }}\right)$ of the electrochemical Si-C systems (cells). Accordingly, Figure 7a illustrates that the $R_{\text {total }}$ value of Si-GA-C-750 is smaller than that of Si-G-C-750, i.e.; $\sim 60 \Omega$ and $\sim 73 \Omega$, respectively; indicating the positive impact of the GA carbon precursor on the charge transfer properties of the composite electrode.

Considering the EIS analyses after the C-rate tests, the experimental Nyquist plots illustrate two fairly separated semicircles which is more evident for the Si-G-C-750 sample (Figure 7b), indicating the presence of multiple processes occurring with sufficiently different time constants. The experimental EIS data obtained after C-rate tests is fitted using the equivalent circuits shown in the insets of Figure 7c and 7d. The HF intercept of the real part of the impedance (R1) is attributed to the several effects. 
Aside from the main contribution from electrolyte resistance, the electronic conduction between the substrate and any electronic contact resistances associated with the cell hardware, current collectors and electrode materials are also accounted as R1 [37-40]. The HF depressed semicircle can be interpreted with a resistor associated with SEI formation (R2) (lower conductivity than the liquid electrolyte) and a capacitor placed in parallel (polarisation of the surface layer) (Q1) [37]. The medium-frequency depressed semicircle can be represented with the charge transfer resistance (R3) and the electrical double layer capacitance (Q2) of the passive film/electrode interface [37-39]. The LF region of the Nyquist plots present the Warburg impedance (W) and this $45^{\circ}$ portion corresponds to a frequency range where the kinetics of the system is limited by the rate of the diffusional process [37-39]. The fitted EIS data demonstrate that Si-GA-C-750 sample has a lower total resistance value of $\mathrm{R}_{\text {total }}$ : $101.93 \mathrm{ohm}$ (R1: 5.78

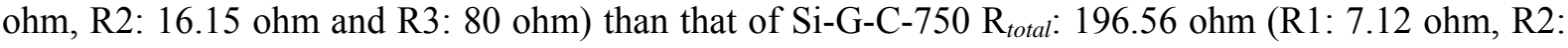
$22.12 \mathrm{ohm}$ and R3: $167.32 \mathrm{ohm}$ ) which is attributed to the fact that the $\mathrm{N}$ functional group in the structure of the glucosamine precursor contributes to the electronic conductivity of the composite material (SiGA-C-750) (Figure 7c and 7d).

Furthermore, to be able to unravel the impact of the carbon precursor on the diffusion coefficient of $\mathrm{Li}^{+}$, the Warburg region of the Nyquist plots are examined. The Warburg impedance is associated to the Warburg coefficient $\left(\sigma_{\mathrm{w}}\right)$ which is obtained via the slope of the real part of the impedance $\left(Z_{R e}\right)$ (in Figure 7c and 7d) versus inverse square root of the angular frequency $\left(\omega^{-0.5}\right.$, where $\left.\omega=2 \pi f\right)$ curves. The following equation provides this relationship: [41]

$Z_{R e}=R_{2}+R_{3}+\sigma \omega^{-0.5}$

Accordingly, the $\sigma_{\mathrm{w}}$ is obtained via the slope of $Z_{R e}$ versus $\omega^{-0.5}$ curve as shown in Figure 7e, where a smaller slope is estimated for Si-GA-C-750 compared with Si-G-C-750. It is important to note that the Warburg coefficient $\left(\sigma_{\mathrm{w}}\right)$ is inversely proportional to $\mathrm{Li}^{+}$diffusion coefficient as follows:

$D_{L i+}=\frac{R^{2} T^{2}}{2 n^{4} A^{2} F^{4} C^{2} \sigma^{2}}$

where $\mathrm{R}$ is the gas constant $(8.314 \mathrm{~J} / \mathrm{mol} . \mathrm{K}), T$ is the temperature $(298 \mathrm{~K}), n$ is the number of electrons transferred in the electrochemical reaction, $A$ is the surface area of electrode $\left(\mathrm{cm}^{2}\right), F$ is the Faraday constant $(96500 \mathrm{C} / \mathrm{mol}), C$ is the molar concentration of $\mathrm{Li}^{+}$in the electrolyte $\left(\mathrm{mol} / \mathrm{cm}^{3}\right)$.

Smaller Warburg coefficient obtained for Si-GA-C-750 compared with Si-G-C-750 (i.e. the angle of inclination of the straight line drawn for Si-GA-C-750 sample is smaller than that of Si-G-C-750) suggests that the lithium-ion diffusion is faster in the $\mathrm{N}$-doped (glucosamine) containing anode material (Figure 7e). 
With the help of slopes of the linear equation relationships between $Z_{R e}$ and $\omega^{-1 / 2}$ at the low-frequency regions (Figure 7e), the $D_{L i+}$ values were calculated to be $3.45 \times 10^{-11} \mathrm{~cm}^{2} / \mathrm{s}$ for Si-GA-C-750 and $1.68 \times 10^{-13} \mathrm{~cm}^{2} / \mathrm{s}$ for Si-G-C-750. It is noted that the outcomes of the EIS analyses are in good agreement with the hypothesis that $\mathrm{N}$ functional group may bring unique features into the $\mathrm{Si}$ anode material, such as high-electronic conductivity, fast-ionic mobility and electrochemical stability.

\section{Conclusions}

An alternative pathway to nanostructured $\mathrm{Si}-\mathrm{C}$ composites materials through the microwave assisted Hydrothermal Carbonization (HTC) was introduced. In contrast to the energy consuming and costly technologies generally used for the production of carbonaceous materials, HTC represents a green and sustainable approach. Taking this approach one step further, microwave assisted HTC method gives rise to much rapid material synthesis resulting high energy efficiency and good homogeneity at the structure. To do so, crystalline silicon cores were coated by a thin layer amorphous carbon shell in the presence of glucose and glucosamine where the latter is pyrolyzed at $750{ }^{\circ} \mathrm{C}$ to obtain resulting anode materials for LIBs. Composite containing glucosamine resulted in N-doped carbon shell evidenced by XPS analysis which contributed to obtain much enhanced electrochemical properties than that of glucose containing counterpart. Accordingly, the best capacity performances were obtained with Si-GA-C-750 anode materials. Higher capacity values obtained with the N-doped carbon shell are attributed to the enhanced electronic conductivity resulting faster $\mathrm{Li}$ ion diffusion that lower the irreversible capacity loss.

\section{Acknowledgments}

The authors thank to Adem Sen for XRD, Ahmet Nazim for SEM and Sandra Casale for TEM measurements.

\section{References}

[1] D. Larcher, J.M. Tarascon, Nature Chemistry 7 (2015) (1) 19.

[2] A. Yoshino, Angewandte Chemie-International Edition 51 (2012) (24) 5798.

[3] J.G. Ren, Q.H. Wu, G. Hong, W.J. Zhang, H.M. Wu, K. Amine, J.B. Yang, S.T. Lee, Energy Technology 1 (2013) (1) 77.

[4] K. Feng, M. Li, W.W. Liu, A.G. Kashkooli, X.C. Xiao, M. Cai, Z.W. Chen, Small 14 (2018) (8).

[5] X.L. Li, M. Gu, S.Y. Hu, R. Kennard, P.F. Yan, X.L. Chen, C.M. Wang, M.J. Sailor, J.G. Zhang, J. Liu, Nature Communications 5 (2014).

[6] J.H. Miao, C.V. Thompson, Journal of the Electrochemical Society 165 (2018) (3) A650.

[7] A. Mukanova, A. Nurpeissova, S.S. Kim, M. Myronov, Z. Bakenov, Chemistryopen 7 (2018) (1)

92. 
[8] A. Mukanova, A. Nurpeissova, A. Urazbayev, S.S. Kim, M. Myronov, Z. Bakenov, Electrochimica Acta 258 (2017) 800.

[9] T. Munaoka, X.Z. Yan, J. Lopez, J.W.F. To, J. Park, J.B.H. Tok, Y. Cui, Z.N. Bao, Advanced Energy Materials 8 (2018) (14).

[10] D. Bresser, D. Buchholz, A. Moretti, A. Varzi, S. Passerini, Energy \& Environmental Science 11 (2018) (11) 3096.

[11] Z.H. Wu, J.Y. Yang, B. Yu, B.M. Shi, C.R. Zhao, Z.L. Yu, Rare Metals 38 (2019) (9) 832.

[12] M.A. Rahman, G.S. Song, A.I. Bhatt, Y.C. Wong, C.E. Wen, Advanced Functional Materials 26 (2016) (5) 647.

[13] J.R. Szczech, S. Jin, Energy \& Environmental Science 4 (2011) (1) 56.

[14] Y.L. An, H.F. Fei, G.F. Zeng, L.J. Ci, S.L. Xiong, J.K. Feng, Y.T. Qian, Acs Nano 12 (2018) (5) 4993.

[15] C. Wang, J.M. Yu, S.H. Li, Z.D. Lu, Chemical Engineering Journal 370 (2019) 1019.

[16] Y.P. Wu, X.K. Huang, L. Huang, X.R. Guo, R. Ren, D. Liu, D.Y. Qu, J.H. Chen, Acs Applied Energy Materials 1 (2018) (4) 1395.

[17] G. Nava, J. Schwan, M.G. Boebinger, M.T. McDowell, L. Mangolini, Nano Letters 19 (2019) (10) 7236.

[18] L. Tong, P. Wang, A.R. Chen, F. Qiu, W.Z. Fang, J. Yang, C. Wang, Y. Yang, Carbon 153 (2019) 592.

[19] H.W. Kim, D.J. Lee, H. Lee, J. Song, H.T. Kim, J.K. Park, J. Mater. Chem. A 2 (2014) (35) 14557.

[20] X. Liu, Z.X. Wang, H.J. Guo, X.H. Li, R. Zhou, Y. Zhou, Ionics 23 (2017) (9) 2311.

[21] R.D. Cakan, M.M. Titirici, M. Antonietti, G.L. Cui, J. Maier, Y.S. Hu, Chem. Commun. (2008) (32) 3759.

[22] M. Sevilla, A.B. Fuertes, Acs Nano 8 (2014) (5) 5069.

[23] B. Hu, K. Wang, L.H. Wu, S.H. Yu, M. Antonietti, M.M. Titirici, Advanced Materials 22 (2010) (7)

813.

[24] M.M. Titirici, R.J. White, N. Brun, V.L. Budarin, D.S. Su, F. del Monte, J.H. Clark, M.J. MacLachlan, Chemical Society Reviews 44 (2015) (1) 250.

[25] L. Zhao, N. Baccile, S. Gross, Y.J. Zhang, W. Wei, Y.H. Sun, M. Antonietti, M.M. Titirici, Carbon 48 (2010) (13) 3778.

[26] S.E. Elaigwu, G.M. Greenway, J. Anal. Appl. Pyrolysis 118 (2016) 1.

[27] I.H. Son, J.H. Park, S. Kwon, S. Park, M.H. Rummeli, A. Bachmatiuk, H.J. Song, J. Ku, J.W. Choi, J.M. Choi, S.G. Doo, H. Chang, Nature Communications 6 (2015).

[28] L. Xu, S. Ashraf, J.P. Hu, P.P. Edwards, M.O. Jones, E. Hadzifejzouic, J.S. Foord, International Journal of Hydrogen Energy 41 (2016) (30) 12730.

[29] A. Touidjine, M. Morcrette, M. Courty, C. Davoisne, M. Lejeune, N. Mariage, W. Porcher, D. Larcher, Journal of the Electrochemical Society 162 (2015) (8) A1466.

[30] Y.S. Hu, R. Demir-Cakan, M.M. Titirici, J.O. Muller, R. Schlogl, M. Antonietti, J. Maier, Angewandte Chemie-International Edition 47 (2008) (9) 1645.

[31] S.N. Faisal, E. Haque, N. Noorbehesht, W.M. Zhang, A.T. Harris, T.L. Church, A.I. Minett, RSC Adv. 7 (2017) (29) 17950.

[32] C. Chen, S.H. Lee, M. Cho, J. Kim, Y. Lee, ACS Applied Materials \& Interfaces 8 (2016) (4) 2658.

[33] C.H. Gan, C.K. Zhang, W.D. Wen, Y.K. Liu, J. Chen, Q.S. Xie, X.T. Luo, Acs Applied Materials \& Interfaces 11 (2019) (39) 35809.

[34] H.M. Cho, Y.J. Park, J.W. Yeon, H.C. Shin, Electronic Materials Letters 5 (2009) (4) 169.

[35] M. Ratyński, B. Hamankiewicz, M. Krajewski, M. Boczar, A. Czerwiński, RSC Advances 8 (2018) (40) 22546.

[36] N. Ding, J. Xu, Y.X. Yao, G. Wegner, X. Fang, C.H. Chen, I. Lieberwirth, Solid State lonics 180 (2009) (2) 222.

[37] D. Dees, E. Gunen, D. Abraham, A. Jansen, J. Prakash, Journal of the Electrochemical Society 152 (2005) (7) A1409.

[38] S. Franger, S. Bach, J. Farcy, J.P. Pereira-Ramos, N. Baffier, Electrochimica Acta 48 (2003) (7) 891. 
[39] F. Paloukis, C. Elmasides, F. Farmakis, P. Selinis, S.G. Neophytides, N. Georgoulas, Journal of Power Sources 331 (2016) 285.

[40] W. Wang, I. Ruiz, K. Ahmed, H.H. Bay, A.S. George, J. Wang, J. Butler, M. Ozkan, C.S. Ozkan, Small 10 (2014) (16) 3389.

[41] X. Yi, W.J. Yu, M.A. Tsiamtsouri, F.Q. Zhang, W.J. He, Q.Y. Dai, S.Y. Hu, H. Tong, J.C. Zheng, B. Zhang, J.Q. Liao, Electrochimica Acta 295 (2019) 719.

\section{Figures}

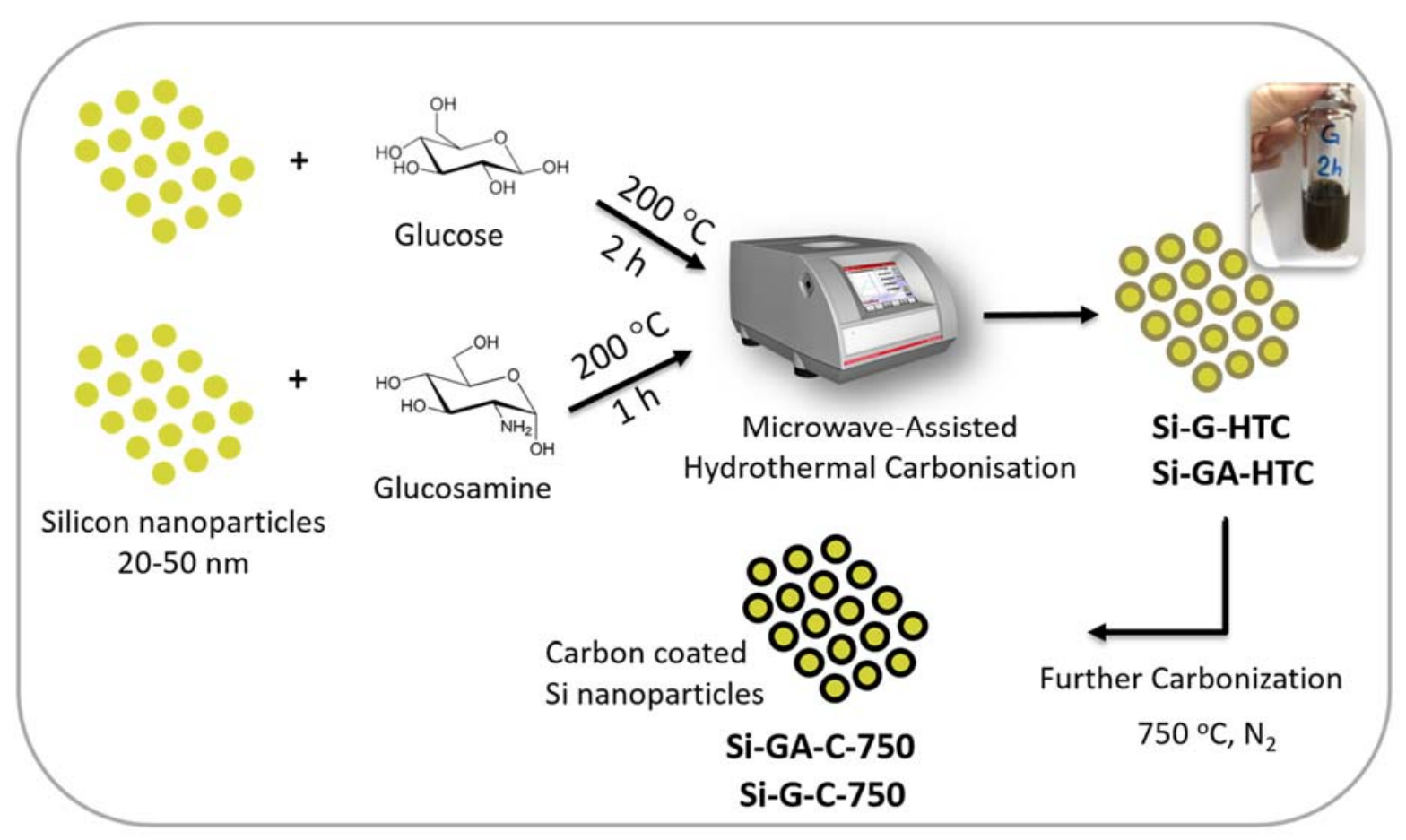


Figure 1. Schematic represantation of synthesis of silicon-carbon anode materials via microwave assisted HTC and further carbonization.
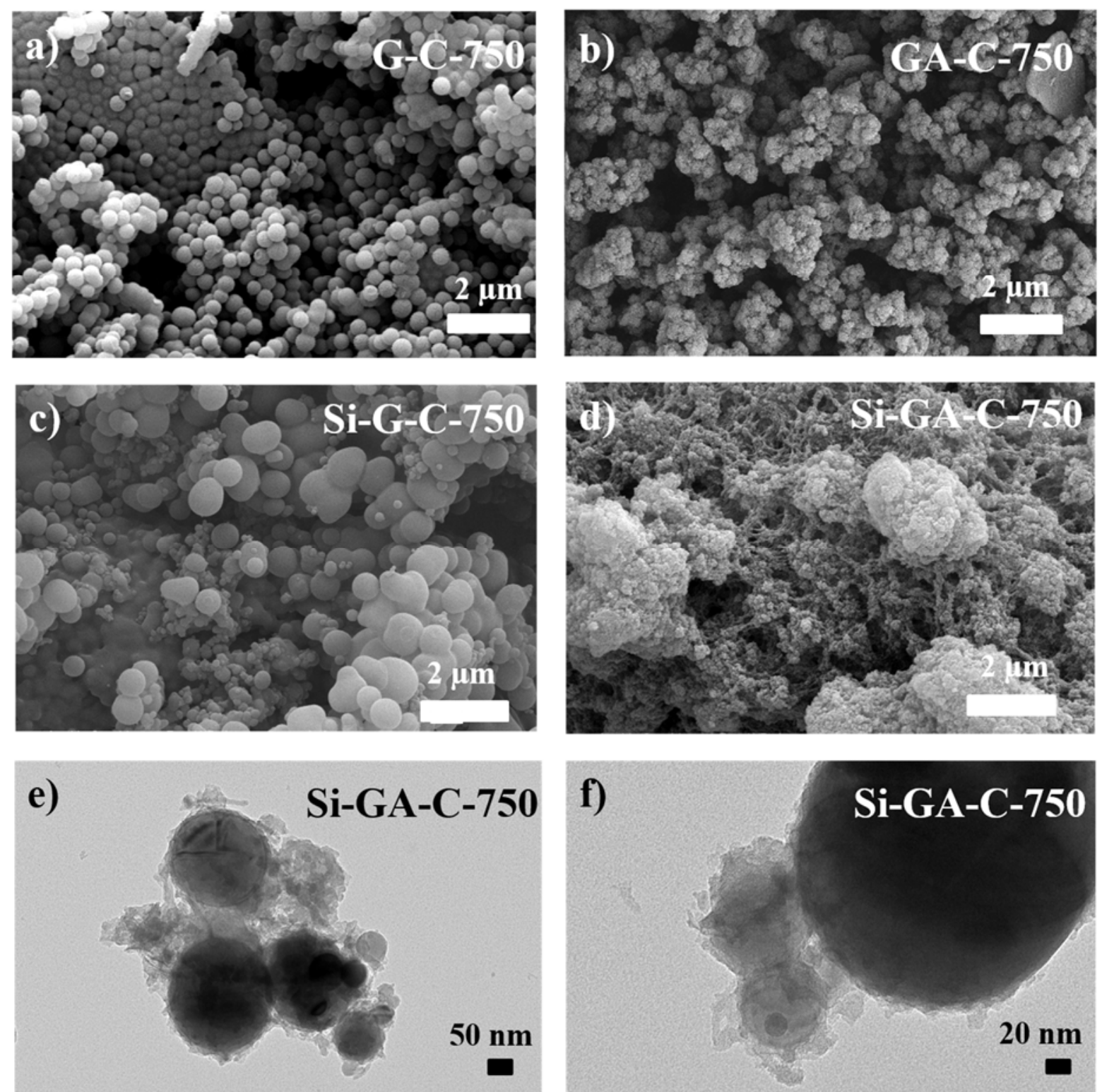

Figure 2. SEM images of a) G-C-750, b) GA-C-750, c) Si-G-C-750, d) Si-GA-C-750, TEM images of e), f) Si-GA-C-750. 

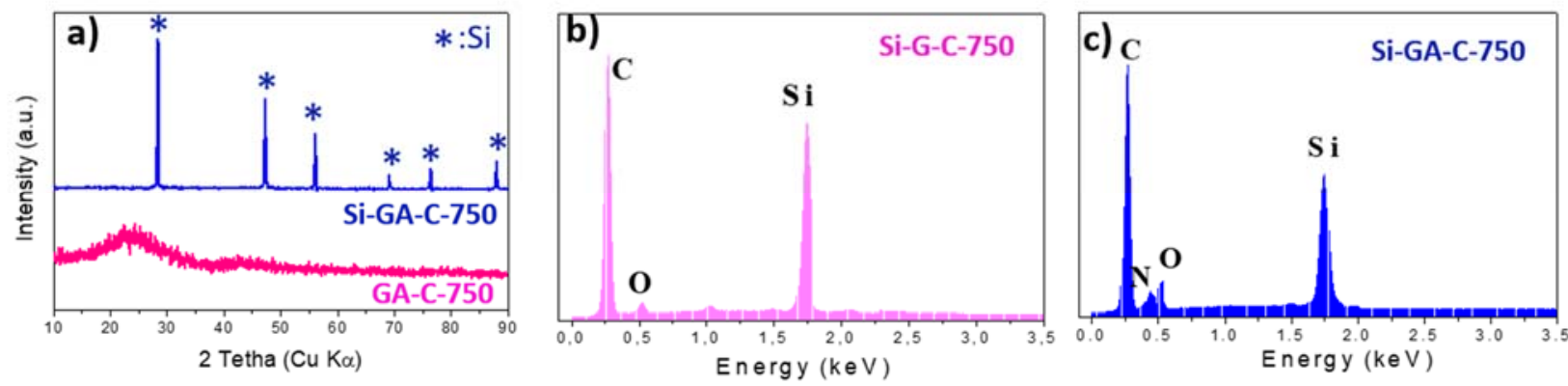

Figure 3. a) XRD patterns of GA-C-750, Si-GA-C-750, b) EDX spectra of Si-G-C-750 and c) EDX spectra of Si-GA-C-750.
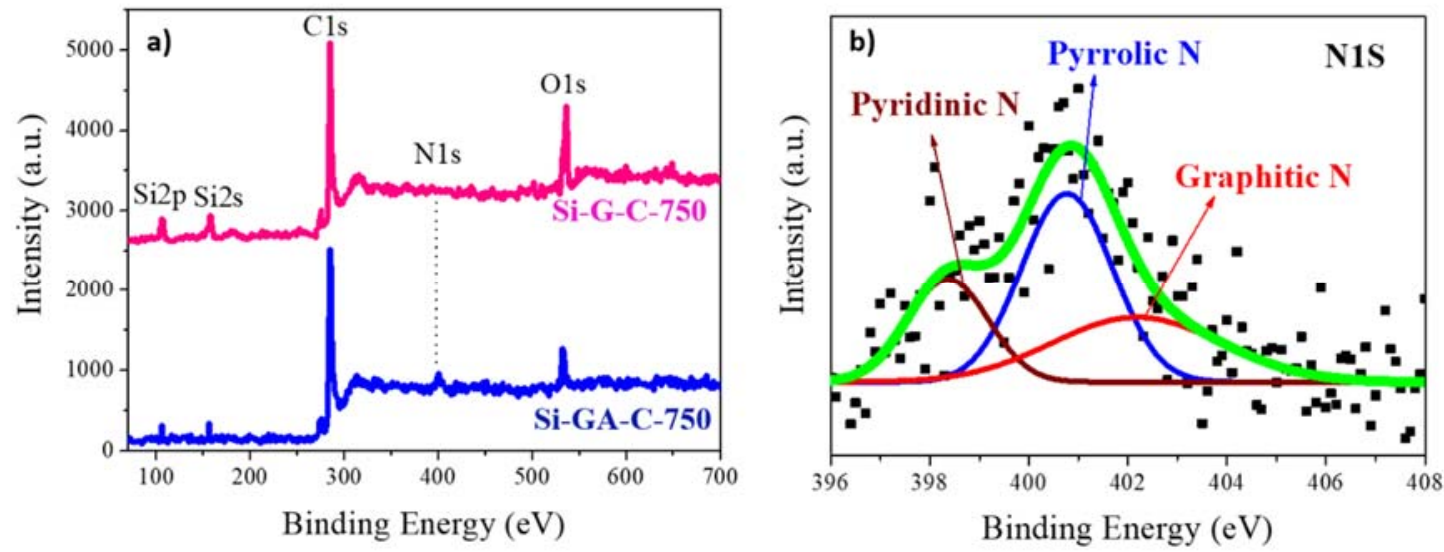

Figure 4. a) XPS spectrum of Si-G-C-750 and Si-GA-C-750 and b) N1s XPS fitting spectrum of SiGA-C-750. 

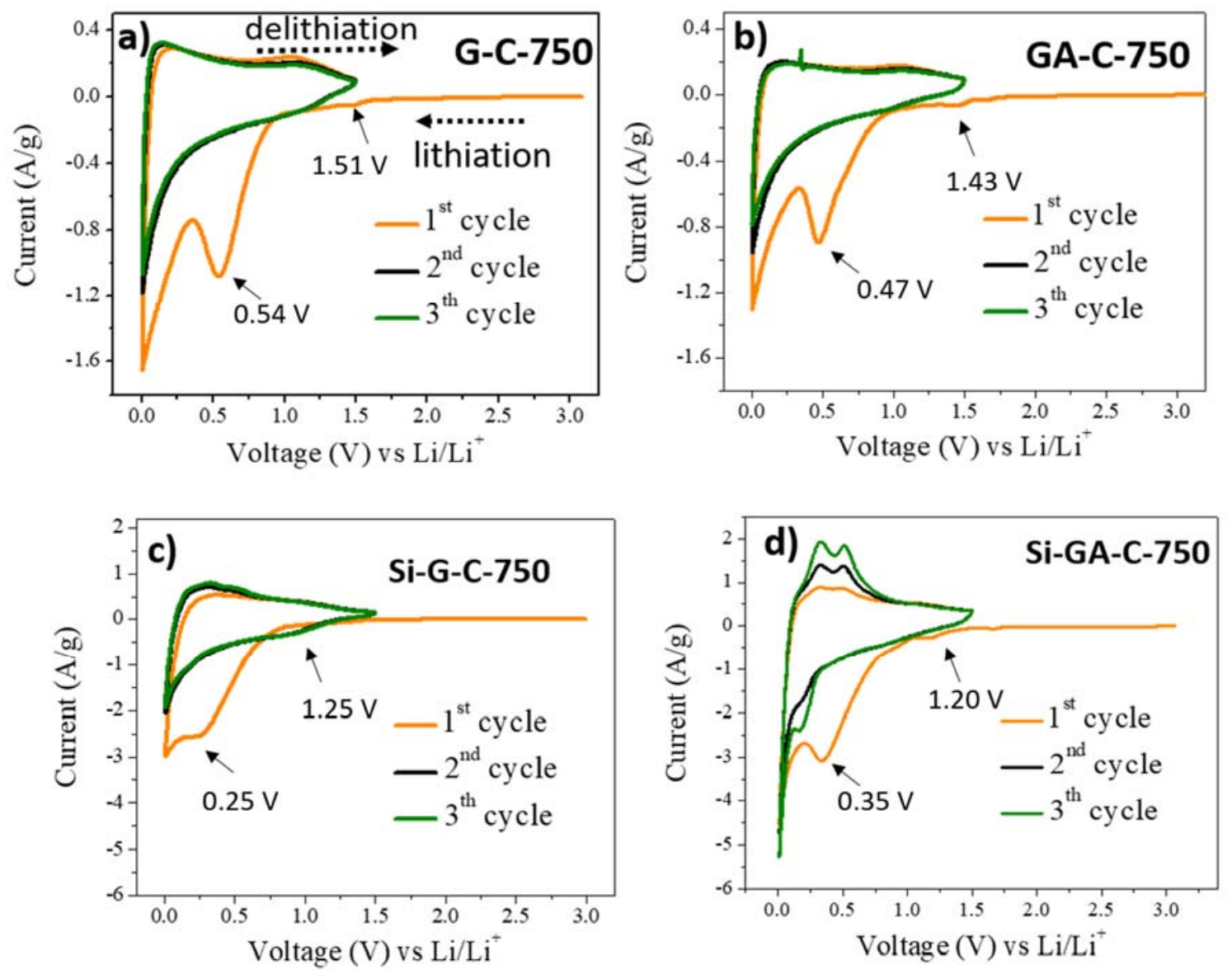

Figure 5. Cyclic voltammograms of a) G-C-750, b) GA-C-750, c) Si-G-C-750, d-) Si-GA-C-750. CV experiments were operated at a scan rate of $0.1 \mathrm{mV} / \mathrm{s}$. 

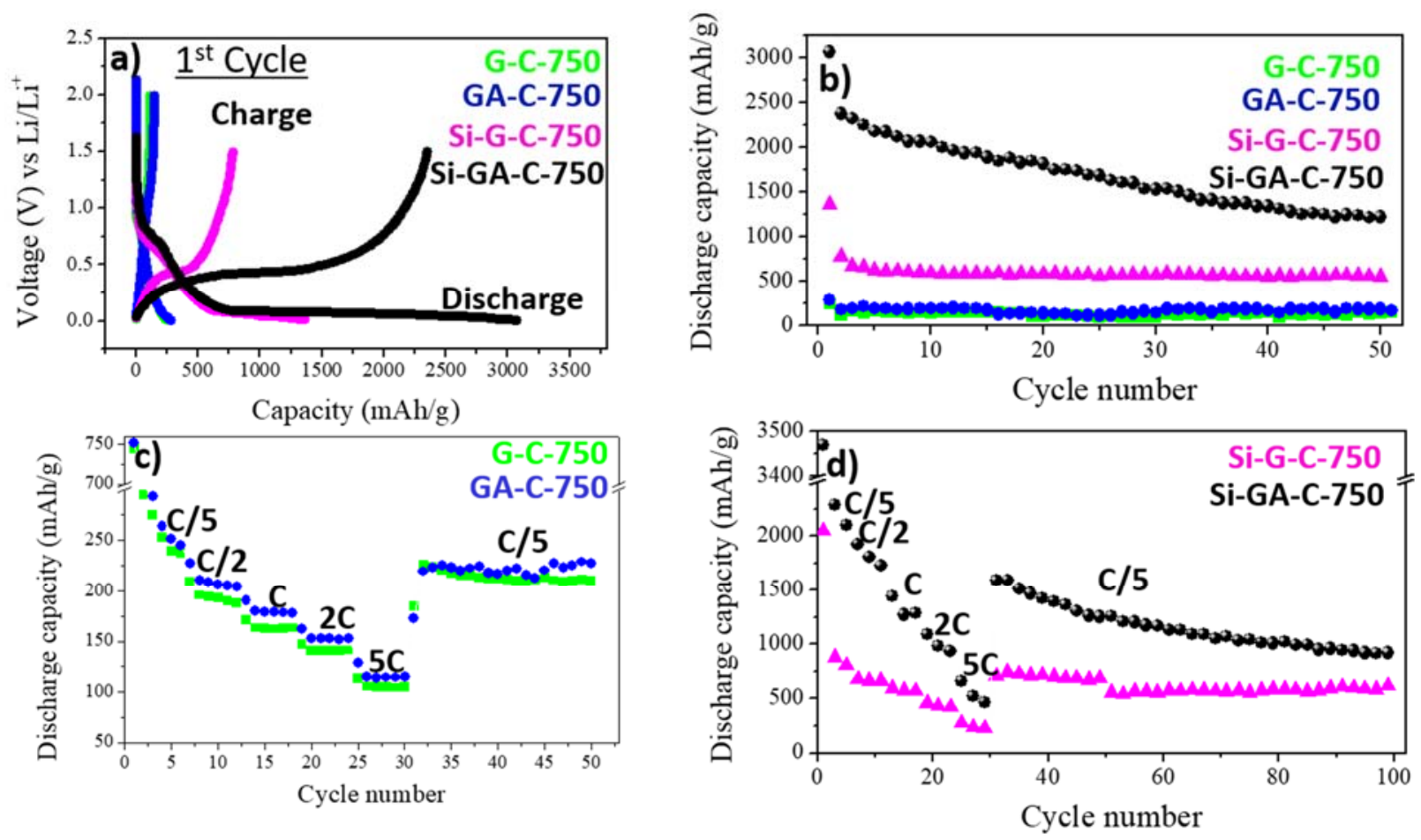

Figure 6. a) Galvanostatic charge/discharge curves of G-C-750, GA-C-750, Si-G-C-750 and Si-GA-C750 at $1^{\text {st }}$ cycle, b) discharge capacities of G-C-750, GA-C-750, Si-G-C-750 and Si-GA-C-750. The rate performances of c) G-C-750, GA-C-750 and d) Si-G-C-750, Si-GA-C-750. Note: capacities were calculated based on silicon mass of the Si-G-C-750 and Si-GA-C-750 composites 

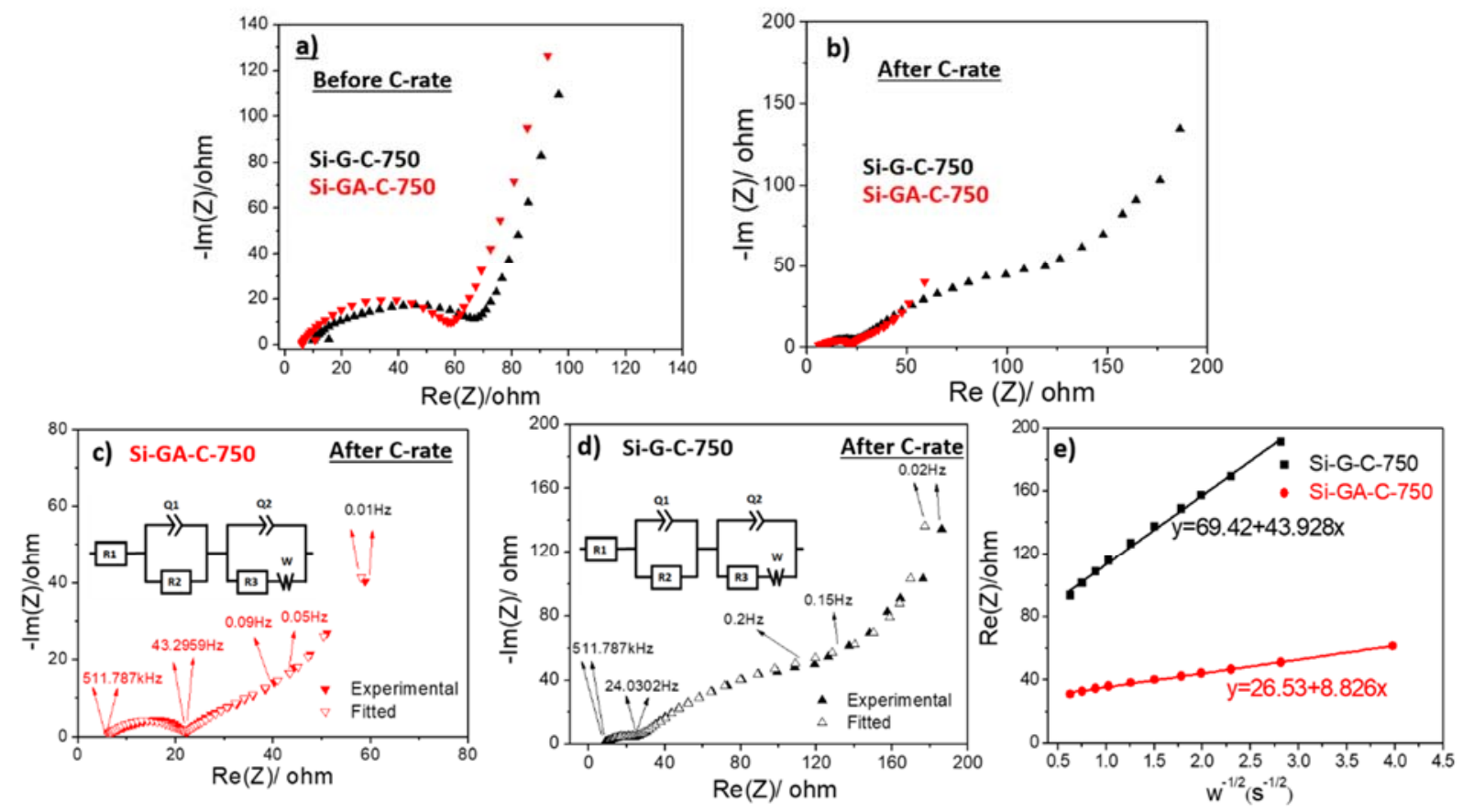

Figure 7. Nyquist plot of the Si-G-C-750 and Si-GA-C-750 a) before and b) after C rate cycling. The experimental and equivalent circuit fitting curves of the c) Si-GA-C-750 and d) Si-G-C-750, e) the linear relationship between $\operatorname{Re}(\mathrm{Z})$ and $\omega^{-1 / 2}$ at low frequency for the Si-G-C-750 and Si-GA-C-750. 


\title{
SUPPORTING INFORMATION
}

\section{Prompt Microwave-Assisted Synthesis of Carbon Coated Si Nanocomposites as Anode for Lithium-Ion Batteries}

\author{
Ali Uctepe ${ }^{\mathrm{a}, \mathrm{b}}$, Emrah Demir ${ }^{\mathrm{a},}$, Burak Tekin ${ }^{\mathrm{a}, \mathrm{b}}$, Burcu Dursun ${ }^{\mathrm{a}, \mathrm{c}}$, Osman Ozturk ${ }^{\mathrm{a}, \mathrm{d}}$, Ozlem Sel $^{\mathrm{e}}$, Rezan \\ Demir-Cakan $^{\mathrm{a}, \mathrm{b}^{*}}$
}

${ }^{a}$ Institute of Nanotechnology, Gebze Technical University, 41400, Gebze, Kocaeli, Turkey ${ }^{b}$ Department of Chemical Engineering, Gebze Technical University, 41400, Gebze, Kocaeli, Turkey

${ }^{c}$ Department of Material Science and Engineering, Gebze Technical University, 41400, Gebze, Kocaeli, Turkey

${ }^{d}$ Department of Physics, Gebze Technical University, 41400, Gebze, Kocaeli, Turkey ${ }^{e}$ Sorbonne Université, CNRS, Laboratoire Interfaces et Systèmes Electrochimiques, LISE UMR8235, 75005 Paris, France

*Corresponding author e-mail address: demir-cakan@gtu.edu.tr
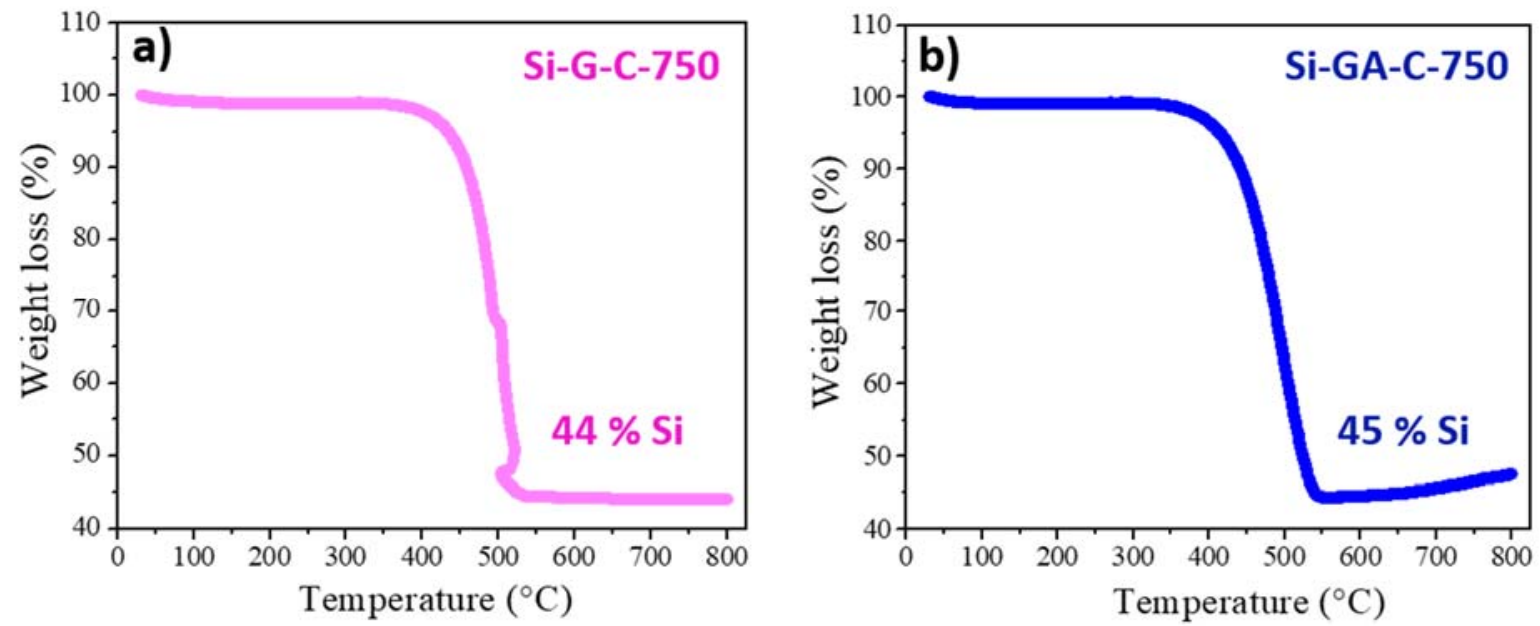

Figure SI-1. TGA curves of a) Si-G-C-750 and b) Si-GA-C-750. 

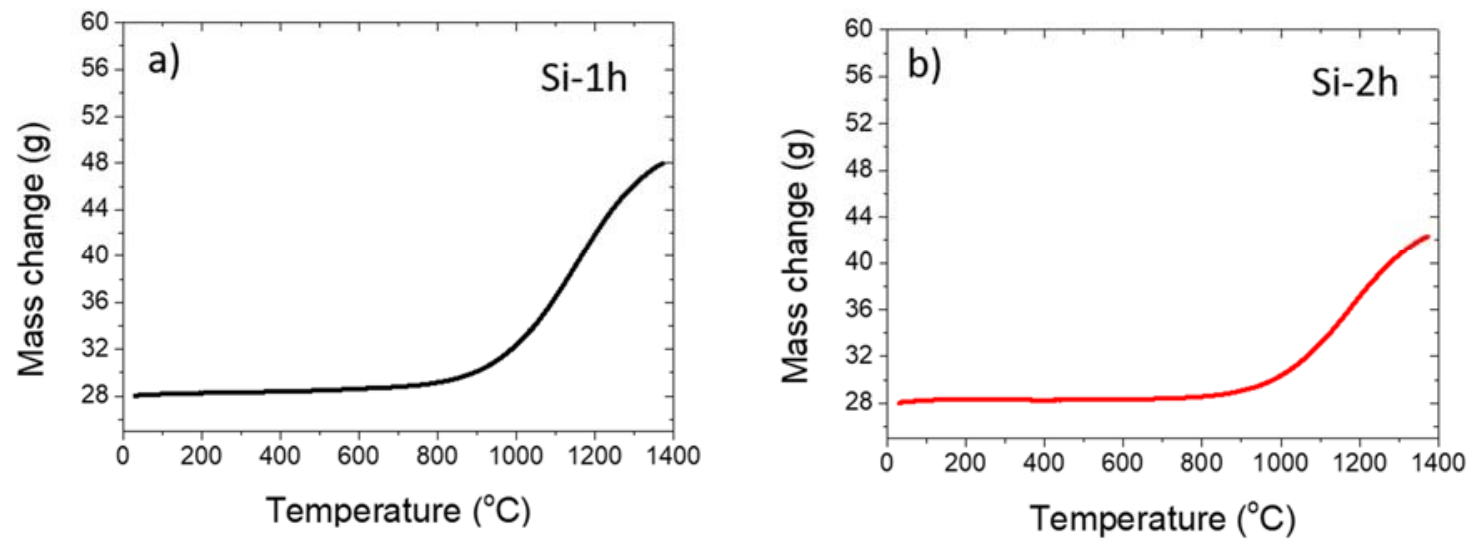

Figure SI-2. TGA curves of silicon particles a) after 1-hour and b) 2-hours of microwave treatment in water.
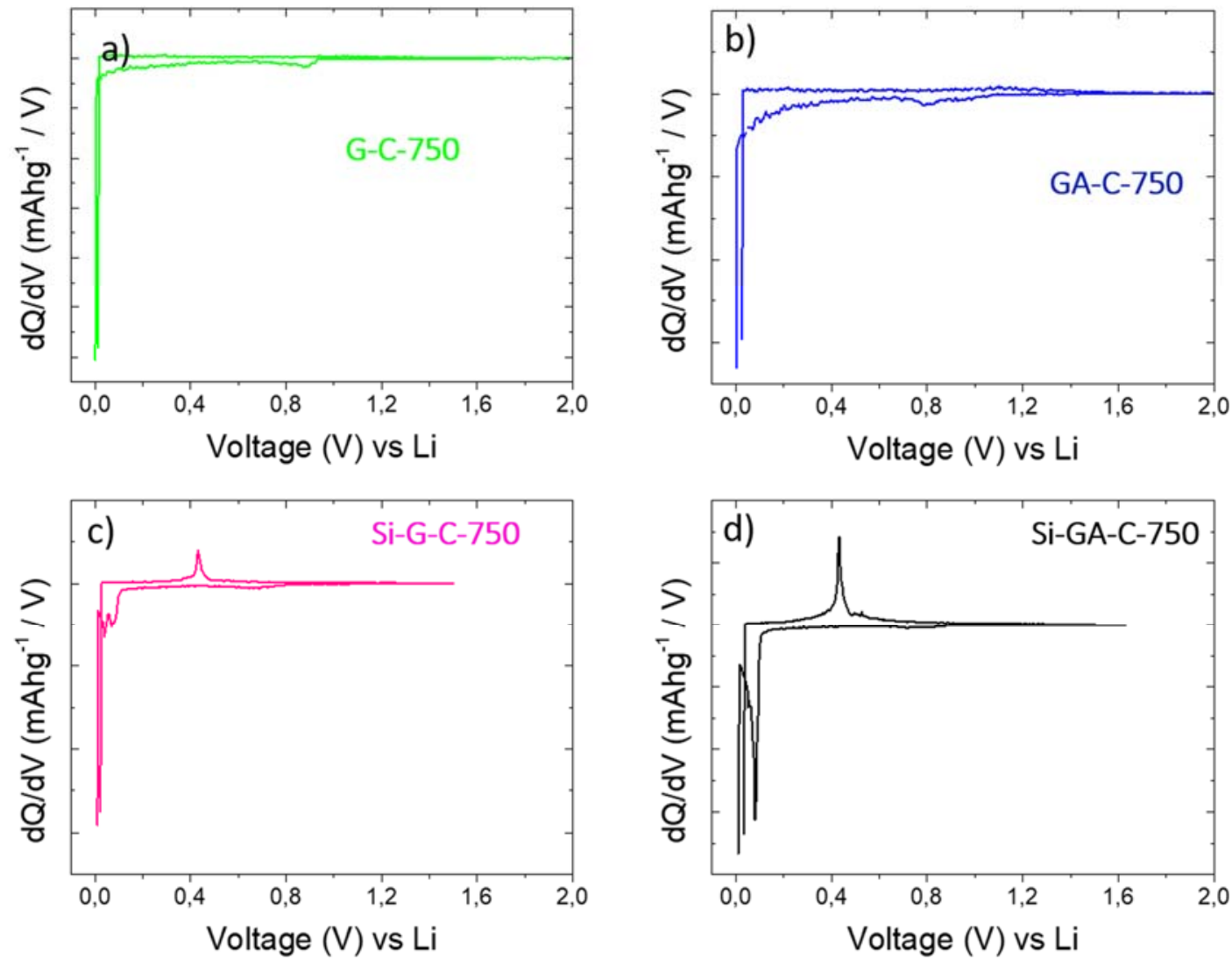

Figure SI-3. dQ / dV plots of the G-C-750, GA-C-750, Si-G-C-750 and Si-GA-C-750 at the first cycle. 
Table SI-1. Yield of $0.5 \mathrm{~g}$ of glucose and glucosamine after the microwave-assisted hydrothermal carbonization method. Note: 0.5 gram of each carbon precursor was dispersed in $10 \mathrm{~mL}$ of water and then subjected to microwave-assisted heat treatment at $200^{\circ} \mathrm{C}$.

\begin{tabular}{|c|c|c|c|c|c|}
\hline \multicolumn{6}{|c|}{ MICROWAVE SYNTHESIS } \\
\hline & & \multicolumn{2}{|c|}{ 1hour } & \multicolumn{2}{|c|}{ 2hour } \\
\hline & & Experiment & Average & Experiment & Average \\
\hline \multirow{5}{*}{ Glucose } & 1 & $0.0012 \mathrm{~g}$ & \multirow{5}{*}{$0,00105 \mathrm{~g}$} & $0.0212 \mathrm{~g}$ & \multirow{5}{*}{$0.02084 \mathrm{~g}$} \\
\hline & 2 & $0.0009 \mathrm{~g}$ & & $0.0208 \mathrm{~g}$ & \\
\hline & 3 & & & $0.0212 \mathrm{~g}$ & \\
\hline & 4 & & & $0.0212 \mathrm{~g}$ & \\
\hline & 5 & & & $0.0198 \mathrm{~g}$ & \\
\hline \multirow{2}{*}{ Glucosamine } & 1 & $0,049 \mathrm{~g}$ & \multirow{2}{*}{$0,04777 \mathrm{~g}$} & $0,0621 \mathrm{~g}$ & \multirow{2}{*}{$0,059 \mathrm{~g}$} \\
\hline & 2 & $0,0463 \mathrm{~g}$ & & $0,0559 \mathrm{~g}$ & \\
\hline
\end{tabular}

